\title{
Communications of the median nerve in foetuses
}

\author{
A.B. Kara, Ö. Elvan, N.C. Öztürk, A.H. Öztürk \\ Department of Anatomy, Faculty of Medicine, Mersin University, Mersin, Turkey \\ [Received: 15 August 2017; Accepted: 30 October 2017]
}

Background: Communications between the median, ulnar and musculocutaneous nerves in the arm, forearm and hand were reported in adult cadaveric and electrophysiological studies. These communicant branches may lead conflicting clinical and electrodiagnostic outcomes. While there are many studies on adult patients or cadavers, there is poor regarding foetuses. The present study was conducted to examine the frequencies of these communications and their coexistences in human foetuses.

Materials and methods: Anterior aspect of the forearms of 50 foetuses (29 females, 20 males, and 1 unknown) were dissected bilaterally (totally 100 sides) for this purpose.

Results: Communications between the median and the musculocutaneous nerves in the arm were found unilaterally in $4 \%$. Communications from the median to the ulnar nerve in the forearm were encountered unilaterally in $22 \%$, and bilaterally in 12\%; from the ulnar to the median nerve in the hand unilaterally in $28 \%$, and bilaterally in $12 \%$. Coexistence of all these variations was not encountered in any foetus. But coexistence of two different types of communicant branch was encountered in $4 \%$.

Conclusions: Precise knowledge of nerve communications, variations and rate of coexistences in foetuses may have significance for clinicians and researchers dealing with subjects in foetal period. (Folia Morphol 2018; 77, 3: 441-446)

Key words: median nerve, ulnar nerve, musculocutaneous nerve, foetus, communication, coexistence

\section{INTRODUCTION}

Anomalous communications among the nerves of the upper extremity have been studied by many authors as they alter the innervation patterns $[2,8$, $11,19,22$ ]. These communicating branches (CBs) may take place either between the median nerve (MN) and musculocutaneous nerve (MCN) or between the MN and ulnar nerve (UN) $[2,13,14,19]$. They may also exist between the anterior interosseous nerve (AIN) and the UN or between the palmar digital branches of the MN and the UN $[5,6,8,13,14]$.

Although no special naming has been encountered for CBs between MN and MCN, specific terms like Martin Gruber (MGA), Marinacci and Berretini anastomosis (BA) have been given for $\mathrm{CBs}$ between MN and UN $[6,7,19]$. When a neural communication takes place between MN and UN in the forearm that involves axons leaving either from the main trunk of MN or AIN, it is called as MGA $[4,6]$. Since MGA is frequent in humans, some authors considered it as a variation rather than an anomaly $[2,11]$. The Marinacci communication is defined as reverse MGA [17, 19]. The sensory communications between common digital nerves that arise from the UN and $M N$ in the palmar surface of the hand is called BA [6].

Communicating branches between the nerves have been attributed to the common ventral nerve trunk that innervates flexor muscles of the upper ex-

Address for correspondence: A.B. Kara, MD, Department of Anatomy, Faculty of Medicine, Mersin University, Çiftlikköy Campus, 33343, Yenisehir, Mersin, Turkey, tel: +90 32436100 01-29076, +90 53056948 33, fax: +90 324341 24 00, e-mail: alev.bobus17@yahoo.com 
tremity during embryogenesis $[2,11,14,21]$. These connections have been accepted to represent the primitive nerve supply of the anterior arm muscles, as the existence of such connections have been observed in monkeys and in some apes by comparative anatomic studies $[16,17]$.

Neural communications between nerves may lead to confusing clinical and electrodiagnostic findings $[2,6,19]$. Thereby, awareness of the diversity of the communications between $\mathrm{MN}$ and the nerves at its vicinity is needed to avoid misdiagnosis of peripheral nerve lesions. The purpose of this study was to put forth the incidences and coexistence of the communications of the MN with MCN or UN along the upper extremity in foetuses and to emphasize its clinical importance.

\section{MATERIALS AND METHODS}

This study was performed on 50 human foetus cadavers at the Anatomy Laboratory of the Faculty of Medicine of Mersin University. The average age was $23.6 \pm 4.7$ weeks (ranging $16-40$ weeks). Ages of the foetuses were determined by using foot lengths. All foetuses ( 29 females, 20 males, and 1 unknown) were abortion materials and kept in formaldehyde solution. They were provided from the Pathology Laboratory of the Faculty of Medicine of Mersin University with the permission of the ethical committee.

In pathological reports, causes for the abortions were recorded as unexplained antepartum death, antepartum haemorrhage and pre-eclampsia. The foetuses which had no morphological anomaly in the upper limbs were included to the study. Anterior aspects of the upper extremities were dissected precisely to reveal the branches of brachial plexuses in all foetuses. The CBs between the nerves were evaluated in terms of the origin, course and localisation. Dissections were performed by using a surgical microscope (Zeiss OPMI Pico) and photographs were taken by Nikon D-300, lens 18-55.

\section{RESULTS}

Findings for the communications of the MN were as follows.

In 2 cases there were $\mathrm{CBs}$ running from $\mathrm{MCN}$ to $\mathrm{MN}$ unilaterally in the arm proximal to the MCN's piercing point of the coracobrachialis muscle just before giving off its terminal branches (Fig. 1). Communicating branches from the $\mathrm{MN}$ to $\mathrm{UN}$ in the forearm were encountered in 17 out of 50 (34\%) foetuses. Thirteen of them were from AIN to UN (26\%)

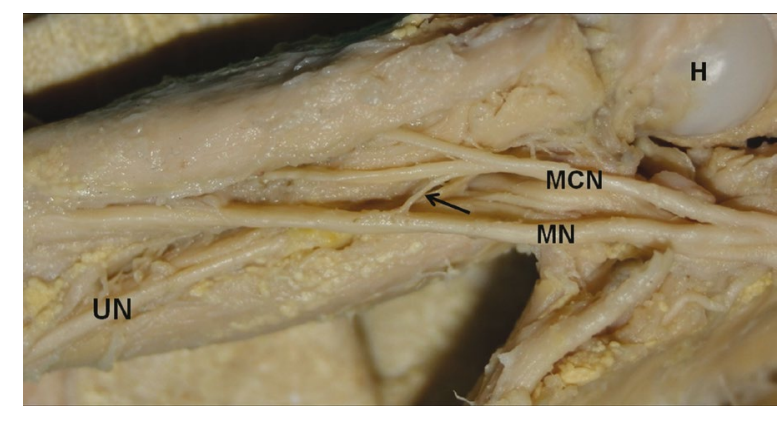

Figure 1. A foetus aged 25 weeks, left side. Photograph showing a communicating branch running from the musculocutaneous nerve to the median nerve (MN); MCN - musculocutaneous nerve; UN - ulnar nerve; $\mathrm{H}$ - head of humerus; black arrow communicating branch.

( 6 bilateral +7 unilateral $=19$ sides) (Fig. 2A). Four of them were from MN trunk to UN (8\%) (all were unilateral) (Fig. 2B). Totally, MGA were encountered in 23 sides (19 from AIN, 4 from MN trunk) out of 100 forearms. The course of CBs was obliquely in all cases. The CBs originated from AIN and joined the UN as a single branch, at the upper half in 17 forearms (Fig. 2A). Only in 2 cases AIN gave 2 branches to join the UN (the upper one ran transversely, the lower obliquely) (Fig. 2C). Any Marinacci communications was not observed in the present study. Communicating branches running between $\mathrm{UN}$ and $\mathrm{MN}$ in the palmar region of the hand were found in $20(40 \%)$ foetuses. The CBs ran from UN to MN (unilaterally in 14 [28\%] and bilaterally in 5 [10\%] cases; Fig. 3A). Only in one case the $\mathrm{CB}$ originated from $\mathrm{MN}$ and joined UN bilaterally in the palmar region (Fig. 3B). The course of CBs was obliquely in all cases (Table 1). In 17 out of 50 foetuses there were not any communications between $\mathrm{MN}$ and MCN or UN either in the arm, forearm or the hand region.

Findings for the coexistence of communications were as follows.

Coexistence of the communicant branches were encountered in 3 of 50 foetuses. In the first case, there was a CB between MCN and MN in the arm and between AIN and UN in the forearm on the right side (Fig. 4A). In second, there was a CB between $M N$ and $\mathrm{UN}$ in the forearm and a CB between $U N$ and $M N$ in the hand on the right side (Fig. 4B). In the third, the CBs were encountered bilaterally. On the right side, one of the CBs was between $\mathrm{MN}$ and $\mathrm{UN}$ in the forearm and the other was between UN and MN in the hand. On the left side, one of the CBs was between AIN and UN in the forearm and the other one was 

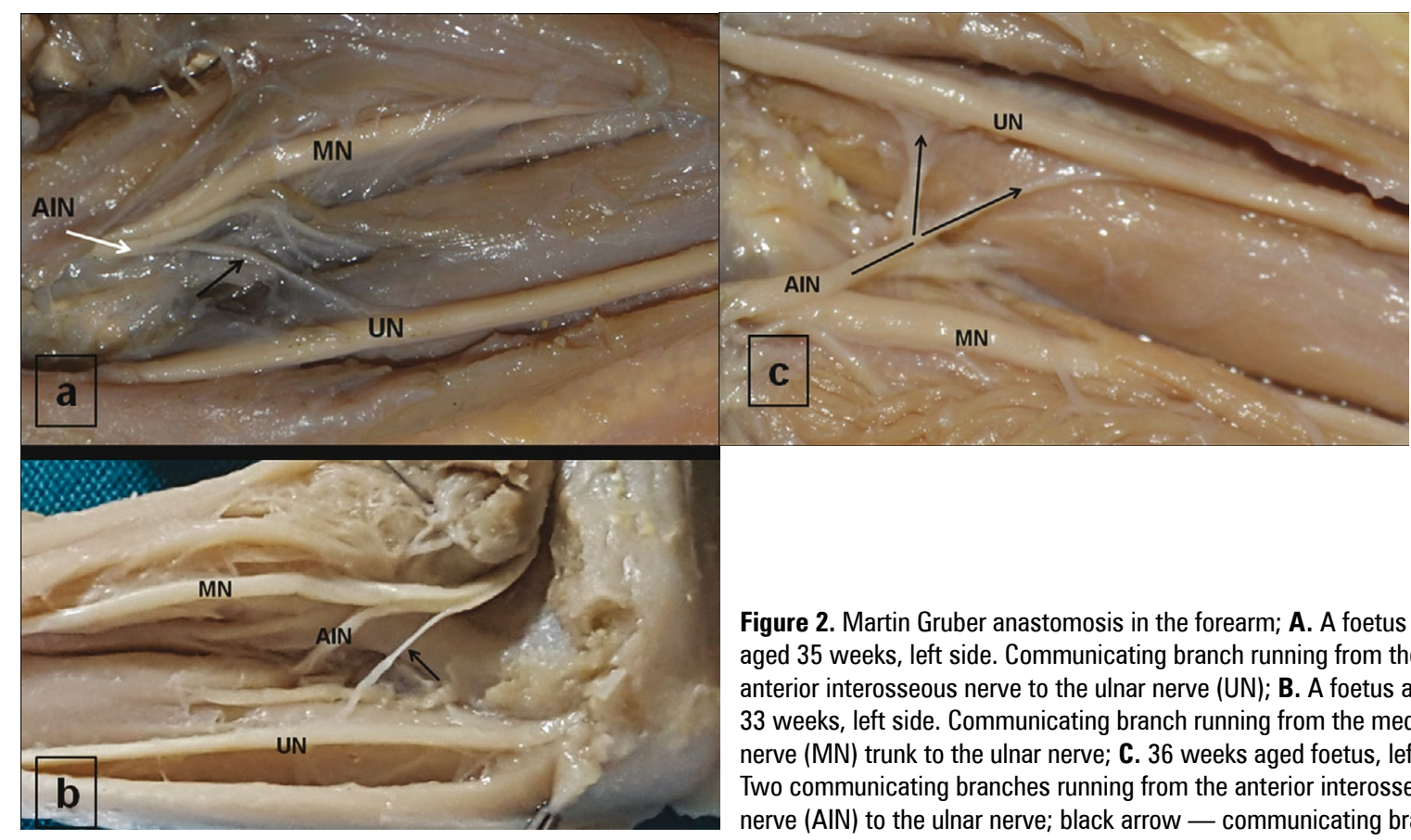

Figure 2. Martin Gruber anastomosis in the forearm; A. A foetus aged 35 weeks, left side. Communicating branch running from the anterior interosseous nerve to the ulnar nerve (UN); B. A foetus aged 33 weeks, left side. Communicating branch running from the median nerve (MN) trunk to the ulnar nerve; C. 36 weeks aged foetus, left side. Two communicating branches running from the anterior interosseous nerve (AIN) to the ulnar nerve; black arrow — communicating branch

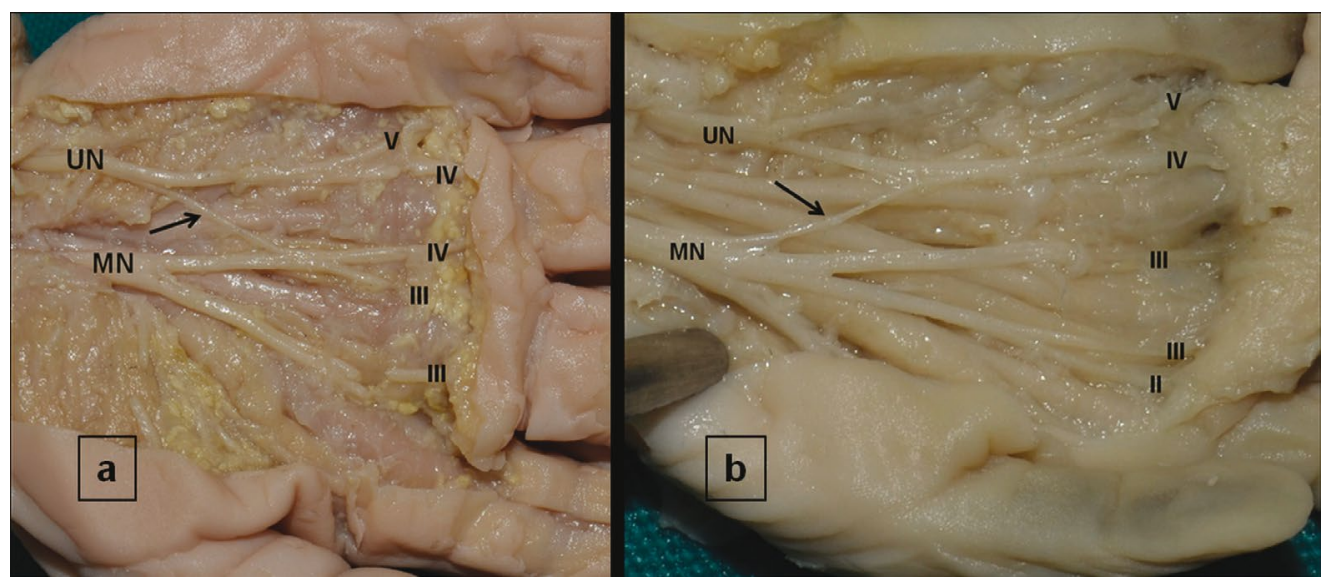

Figure 3. Berretini anastomosis in the palmar region; A. A foetus aged 32 weeks, right side. Communicating branch running from the ulnar nerve (UN) to the median nerve (MN); B. A foetus aged 21 weeks, right side. Communicating branch running from the MN to the UN; II, III, IV — palmar digital nerves of the $2^{\text {nd }}$ to $5^{\text {th }}$ digits; black arrow - communicating branch.

Table 1. Communicating branches regarding regions of the upper limb

\begin{tabular}{lccccc}
\hline Region & Type of communication & No. of foetuses (50) & Unilateral (50) & Bilateral (50) & No. of sides (100) \\
\hline Arm & MN $\rightarrow$ MCN & $\varnothing$ & - & - & - \\
\multirow{3}{*}{ Forearm } & MCN $\rightarrow$ MN & $2(4 \%)$ & $2(4 \%)$ & - & $2(2 \%)$ \\
& MN trunk $\rightarrow$ UN & $4(8 \%)$ & $4(8 \%)$ & - & $4(4 \%)$ \\
& AIN $\rightarrow$ UN & $13(26 \%)$ & $7(14 \%)$ & $6(12 \%)$ & $19(19 \%)$ \\
Hand & UN $\rightarrow$ MN & $\varnothing$ & - & - & - \\
& MN $\rightarrow$ UN & $1(2 \%)$ & & & $24(24 \%)$ \\
\hline
\end{tabular}

AIN — anterior interosseous nerve; MCN — musculocutaneous nerve; MN — median nerve; UN — ulnar nerve 


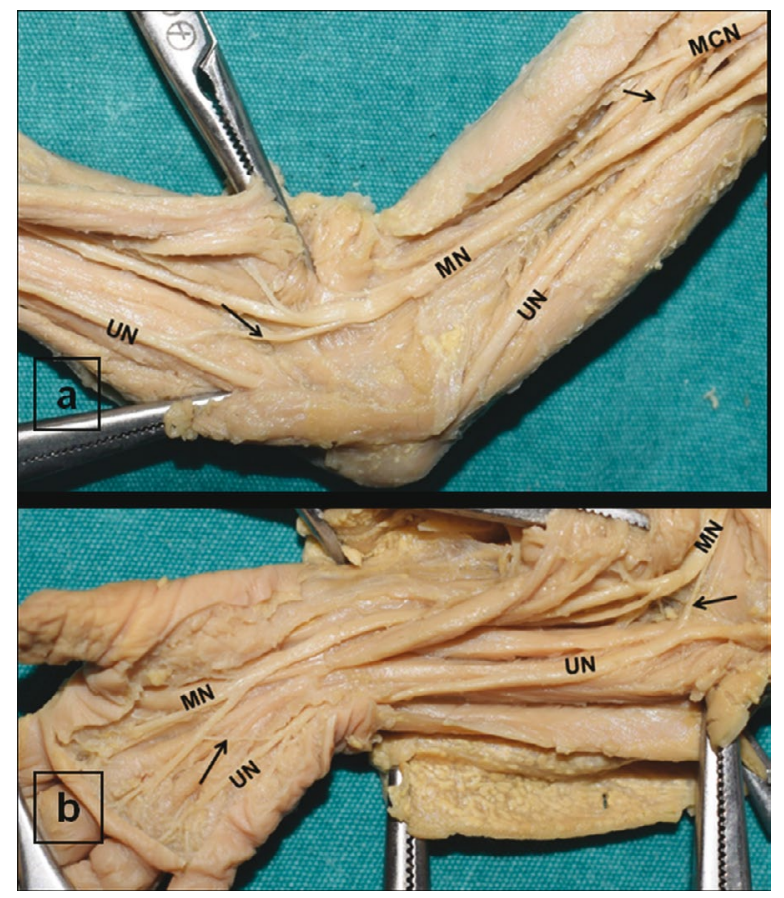

Figure 4. Coexistences in the upper extremity; A. A foetus aged 29 weeks, right side. Coexistence of communicating branch from the musculocutaneous nerve (MCN) to the median nerve (MN) in the arm and Martin Gruber anastomosis in the forearm; B. A foetus aged 25 weeks, right side. Coexistence of Martin Gruber anastomosis in the forearm and Berretini anastomoses in the hand; UN — ulnar nerve; black arrow — communicating branch.

Table 2. Coexistence of communicant branches in the upper extremity

\begin{tabular}{lccc}
\hline & Arm & Forearm & Hand \\
\hline CB in case 1 & MCN to MN (R) & AIN to UN (R) & - \\
CB in case 2 & - & MN to UN (R) & UN to MN (R) \\
CB in case 3 & - & MN to UN (R) & UN to MN (R) \\
& & AIN $\rightarrow$ UN (L) & UN $\rightarrow$ MN (L) \\
\hline
\end{tabular}

AIN — anterior interosseous nerve; $\mathrm{CB}$ — communicant branch; $\mathrm{L}$ — left; MCN — musculocutaneous nerve; $\mathrm{MN}$ - median nerve; $\mathrm{UN}$ - ulnar nerve; $\mathrm{R}$ - right

between UN and MN in the hand. Coexistence of CB observed in 4 out of 100 sides are summarised in Table 2.
The foetuses included to study were in the $2^{\text {nd }}$ $(n=29)$ and $3^{\text {rd }}(n=21)$ trimesters. Evaluation of the type of communicant branches regarding the term of foetuses was given in Table 3 .

\section{DISCUSSION}

There are many reports on the incidences of nerve communications between MN-UN and MN-MCN in adults, but there is not much in foetuses and especially about the coexistence of the $C B s[2,6,8,11$, 16]. Besides leading confusing results in the assessment of nerve injuries, these CBs may also be crucial for the surgeons who treat birth defects of the upper extremities.

The incidence of CBs between MCN and MN is reported to range between $1.4 \%$ and $63.5 \%$ [15]. The most common type of this communication is reported from MCN to MN, while the second is from MN to MCN. In the present study, the CBs were encountered to emerge from the MCN and joined the main trunk of $\mathrm{MN}$ instead of joining the lateral root in 2 cases (Fig. 1). Kosugi et al. [3] proposed that the presence of a supernumerary head of biceps brachii affects the course and branching pattern of the MCN [21]. Likewise, Özturk et al. [11] reported a variation of biceps brachii and coexistence of a communication between MCN and MN.

Martin Gruber anastomosis has been reported to cause confusion in the assessment of nerve injuries, cubital and carpal tunnel syndromes and leprosy neuropathy [14]. In complete lesion of the MN, some muscles may not be paralysed, leading to the erroneous conclusion of the MN being intact [9]. A case of MGA has been reported to mimic conduction block at the elbow site [7]. There are anatomic and electrophysiological studies which report that MGA is predominantly motor in nature $[2,8,11,14$, 16]. This communication has also been reported to provide variations in the innervation of the intrinsic hand muscles [2].

Table 3. Communication types regarding the term of foetuses

\begin{tabular}{|c|c|c|c|c|c|c|c|}
\hline \multirow[t]{2}{*}{ Term } & \multirow[t]{2}{*}{ No. of foetuses } & \multirow[t]{2}{*}{ MCN to MN } & \multicolumn{2}{|c|}{$\begin{array}{l}\text { Martin Gruber } \\
\text { anastomosis }\end{array}$} & \multirow[t]{2}{*}{$\begin{array}{c}\text { Marinacci } \\
\text { anastomosis }\end{array}$} & \multicolumn{2}{|c|}{$\begin{array}{c}\text { Berretini } \\
\text { anastomosis }\end{array}$} \\
\hline & & & MN to UN & AIN to UN & & MN to UN & UN to MN \\
\hline $2^{\text {nd }}$ trimester & 29 & 1 & 2 & 9 & - & 2 & 12 \\
\hline $3^{\text {rd }}$ trimester & 21 & 1 & 2 & 11 & - & - & 14 \\
\hline
\end{tabular}

AIN — anterior interosseous nerve; $\mathrm{MCN}$ - musculocutaneous nerve; $\mathrm{MN}$ — median nerve, UN — ulnar nerve 
Topography of the communication is crucial as the motor deficit of the muscles varies according to the level of the nerve injury [10]. Similar with our findings, MGAs have been reported most common in the upper part of the forearm, and rarely in the distal forearm $[2,8]$. It rarely has an intramuscular course which is reported to be a potential compression site [12]. Uchida and Sugioka [20] stated that when MGA is located close to the medial humeral epicondyle, there might be a significant risk of accidental injury in UN transposition. The CBs may have transverse, oblique or arched course [2]. In the present study, MGAs were observed to run obliquely and two of them were close to the medial humeral epicondyle (Fig. 2B). Generally, MGAs have been reported to be bilateral (10-40\%) but occur more frequently on the right when they are unilateral $[2,11]$. Rodriguez-Niedenführ et al. [13] reported that there is not any statistically significant difference in terms of sexes and sides. Findings of the present study were found concordant with the literature as 7 of 11 unilateral cases were on the right side.

The incidence of MGA has been reported in $5-40 \%$, with an average of $17 \%$ in adults $[7,13]$. In foetuses, its incidence was reported in $15 \%$ by Srinivasan et al. [16] and 7.5\% by Doğan et al. [1]. Doğan et al. [1] also stated that it was less frequent in $2^{\text {nd }}$ trimester than in $3^{\text {rd }}$ trimester. In the present study, concordant with the findings of Doğan et al. [1], MGA was encountered in $19 \%$ of the $2^{\text {nd }}$ term foetuses and in $31 \%$ of the $3^{\text {rd }}$ terms.

The BA has been reported to cause alteration of the middle and ring finger sensibility in another study [18]. A lesion of the MN situated proximal to the emerging point of $a C B$ is reported to affect the thenar muscles, whereas a lesion below that level does not [8]. Stančić et al. [19] reported that BA is a purely sensorial branch and injury of it has been described as an uncomfortable tingling sensation or hyperesthesia. They also concluded BA as a normal anatomical finding rather than a variant, regarding its high rate $(81 \%)$ in their study and in literature reports $(6-100 \%)$ [18]. In the present study, the frequency of BA did not support this statement with a ratio of $26 \%$. It was found in $24 \%(14 / 58)$ in the $2^{\text {nd }}$ trimester and $33 \%$ of $(14 / 42)$ in $3^{\text {rd }}$ trimester.

Reports on traumatic lacerations of the $\mathrm{CBs}$ reveal the importance of the knowledge of the specific anatomy of CBs for surgeons who work superficially to these nerves in the palm. latrogenic injuries in the palmar area are reported to cause loss of sensation between the middle and ring fingers. Thereby, Loukas et al. [7] designated a "risk area" in their studies to provide clinicians for a more accurate preoperative localisation as well as inoperative recognition and preservation. The most common types have been reported as a $C B$ running from the $U N$ to the $M N$ between $3^{\text {rd }}$ and $4^{\text {th }}$ common digital nerves [6]. The CBs encountered in the present study were predominantly from the common digital branch of UN supplying $4^{\text {th }}$ and $5^{\text {th }}$ digits to the common digital branch of MN supplying $3^{\text {th }}$ and $4^{\text {th }}$ digits.

\section{CONCLUSIONS}

In conclusion, all the mentioned CBs may cause differentiation in the innervation patterns and faulty interpretations of electrophysiological tests $[2,20]$. On the other hand, they are reported to be more prone to injuries [22]. Therefore, knowledge of these anastomoses is crucial for correct diagnosis, treatment planning and assessment of traumatic or entrapment lesions of the related nerves. In the present study, all CBs were evaluated along the anterior aspect of the upper extremities in foetus cadavers. There were CBs between MN and MCN or UN in different parts of the upper extremities on 49 sides and coexistence of these different types at the same extremity was encountered only in 4 sides. This paper gives a data about the coexistence of communicating branches in the same extremity. We hope that our findings will contribute to the literature on the coexistence of communicant nerve branches and will lead to studies in larger series.

\section{Acknowledgements}

The authors wish to express their special thanks and respects to foetuses and their families who make contribution to the study by donating their bodies.

\section{REFERENCES}

1. Dogan UN, Uysal II, Karabulut AK, et al. The motor branches of median and ulnar nerves that innervate superficial flexor muscles: a study in human fetuses. Surg Radiol Anat. 2010; 32(3): 225-233, doi: 10.1007/s00276-009-0580-1, indexed in Pubmed: 19876585.

2. Kazakos KJ, Smyrnis A, Xarchas KC, et al. Anastomosis between the median and ulnar nerve in the forearm. An anatomic study and literature review. Acta Orthop Belg. 2005; 71(1): 29-35, indexed in Pubmed: 15792204.

3. Kosugi K, Mortia T, Yamashita H. Branching pattern of the musculocutaneous nerve.1. Cases possessing normal bíceps brachii. Jikeakai Med J. 1986; 33: 63-71.

4. Kumar N, Guru A, D'Souza MR, et al. Incidences and clinical implications of communications between musculocutaneous nerve and median nerve in the arm - a cadaveric 
study. West Indian Med J. 2013; 62(8): 744-747, indexed in Pubmed: 25014861.

5. Lee KS, Oh CS, Chung IH, et al. An anatomic study of the Martin-Gruber anastomosis: electrodiagnostic implications. Muscle Nerve. 2005; 31(1): 95-97, doi: 10.1002/ mus.20141, indexed in Pubmed: 15389650.

6. Leibovic SJ, Hastings H. Martin-Gruber revisited. J Hand Surg Am. 1992; 17(1): 47-53, doi: 10.1016/03635023(92)90112-3, indexed in Pubmed: 1538112.

7. Loukas $M$, Louis RG, Stewart $L$, et al. The surgical anatomy of ulnar and median nerve communications in the palmar surface of the hand. J Neurosurg. 2007; 106(5): 887-893, doi: 10.3171/jns.2007.106.5.887, indexed in Pubmed: 17542535.

8. Marras C, Midroni G. Proximal Martin-Gruber anastomosis mimicking ulnar neuropathy at the elbow. Muscle Nerve. 1999; 22(8): 1132-1135, indexed in Pubmed: 10417799.

9. Nakashima T. An anatomic study on the Martin-Gruber anastomosis. Surg Radiol Anat. 1993; 15(3): 193-195, indexed in Pubmed: 8235961.

10. Narayana K, Narendiran K, Shetty KP. and Prashanthi N. A case of coexistence of three anatomical Variations in the forearm: Gantzer's muscles, Martin-Gruber anastomosis, and nerve of Henle. Eur J Anat. 2004; 8(2): 81-84.

11. Oztürk NC, Uzmansel D, Oztürk H. An unreported pattern of musculocutaneous and median nerve communication with multiple variations of biceps brachii: a case report. Surg Radiol Anat. 2010; 32(9): 887-890, doi: 10.1007/ s00276-009-0616-6, indexed in Pubmed: 20049596.

12. Prates LC, Clóris de, Prates JC, etal. and Marretto Esquisatto MA. The Martin-Gruber Anastomosis in Brazilians: An Anatomical Study. Braz J Morphol Sci. 2003; 20(3): 177-180.

13. Rodriguez-Niedenführ $M$, Vazquez $T$, Ferreira $B$, et al. Intramuscular Martin-Gruber anastomosis. Clin Anat. 2002; 15(2): 135-138, doi: 10.1002/ca.1108.
14. Rodriguez-Niedenführ M, Vazquez T, Parkin I, et al. Martin-Gruber anastomosis revisited. Clinical Anatomy. 2002; 15(2): 129-134, doi: 10.1002/ca.1107.

15. Sarikcioglu L, Sindel M, Ozkaynak S, et al. Median and ulnar nerve communication in the forearm: an anatomical and electrophysiological study. Med Sci Monit. 2003; 9(9): BR351-BR356, indexed in Pubmed: 12960925.

16. Srinivasan R, Rhodes J. The median-ulnar anastomosis (Martin-Gruber) in normal and congenitally abnormal fetuses. Arch Neurol. 1981; 38(7): 418-419, indexed in Pubmed: 6454405.

17. Stancić MF, Burgić N, Mićović V. Marinacci communication. Case report. J Neurosurg. 2000; 92(5): 860-862, doi: 10.3171/jns.2000.92.5.0860, indexed in Pubmed: 10794302.

18. Stancić MF, Mićović V, Potocnjak M. The anatomy of the Berrettini branch: implications for carpal tunnel release. J Neurosurg. 1999; 91(6): 1027-1030, doi: 10.3171/ jns.1999.91.6.1027, indexed in Pubmed: 10584850.

19. Sundaram SM, Sundar B, Arunkumar MJ. Marinacci communication: an electrophysiological study. Clin Neurophysiol. 2003; 114(12): 2334-2337, indexed in Pubmed: 14652092.

20. Uchida Y, Sugioka Y. Electrodiagnosis of Martin-Gruber connection and its clinical importance in peripheral nerve surgery. J Hand Surg Am. 1992; 17(1): 54-59, indexed in Pubmed: 1311344.

21. Uyaroğlu FG. Anastomotic branch from the median nerve to the musculocutaneous nerve: a case report. Anatomy. 2008; 2: 63-66, doi: 10.2399/ana.08.063.

22. Uzun A, Seelig LL. A variation in the formation of the median nerve: communicating branch between the musculocutaneous and median nerves in man. Folia Morphol. 2001; 60(2): 99-101, indexed in Pubmed: 11407150. 